\title{
PENERAPAN ALGORITMA JARINGAN SARAF TIRUAN (JST) DALAM PERKIRAAN HARGA TANAH
}

\author{
Hendra Sanjaya \\ Fakultas Teknologi Informasi \\ Universitas Islam Kalimantan Muhammad Arsyad Al Banjari Banjarmasin \\ Hendrasanjaya25@gmail.com
}

\begin{abstract}
ABSTRAK
Permasalahan utama dalam pembebasan lahan atau pengadaan tanah sering kali terkait pada masalah besarnya ganti rugi yang diberikan oleh pemerintah, menjadi persoalan apabila pemegang hak atas tanah menuntut besarnya ganti rugi atas tanah berdasarkan harga pasar yang berlaku pada saat ini, Pemerintah Daerah ataupun investor yang memerlukan tanah menetapkan besarnya ganti rugi atas tanah cenderung hanya berdasarkan Nilai Jual Obyek Pajak (NJOP). Pada penelitian ini mencoba menerapkan algoritma jaringan syaraf tiruan (JST) yang merupakan model Algoritma Komputasi yang berkembang sangat pesat, dapat bekerja seperti sistem syaraf biologis yaitu dapat mengenali pola-pola yang telah diajarkan. Pada penelitian yang dilasanakan ini untuk mendapatkan perkiraan harga tanah yang ideal, dengan lokasi penelitian di kota Banjarmasin. Adanya hasil dari penelitian ini diharapkan dapat digunakan membantu pemerintah terkait pembebasan tanah dalam besarnya ganti rugi hak atas tanah yang sebelumnya hanya cenderung berdasarkan Nilai Jual Obyek Pajak (NJOP).
\end{abstract}

Kata Kunci : $\quad$ Algoritma Jaringan Syaraf Tiruan, Perkiraan, Harga Tanah

\section{LATAR BELAKANG}

Permasalahan utama dalam pembebasan tanah sering kali terkait pada masalah besarnya ganti rugi yang diberikan oleh pemerintah, menjadi persoalan apabila pemegang hak atas tanah menuntut besarnya ganti rugi atas tanah berdasarkan harga pasar yang berlaku pada saat ini, sedangkan Pemerintah, Pemerintah Daerah ataupun investor yang memerlukan tanah menetapkan besarnya ganti rugi atas tanah cenderung hanya berdasarkan Nilai Jual Obyek Pajak (NJOP).
Apabila dasar perhitungan ganti rugi atas tanah didasarkan atas NJOP Pajak Bumi dan Bangunan pada tahun terakhir, maka hal ini akan menyebabkan negosiasi yang lambat dan berlarut-larut, karena sangat sukar didapatkan kesepakatan harga.

Penggunaan harga tanah juga penting dalam manajemen penggunaan dan pemanfaatan ruang perkotaan. Dengan mengetahui tinggi rendahnya harga tanah, arah perkembangan kota dapat diprediksi. Di pusat kota yang padat, harga tanah cenderung tinggi dan harganya akan menurun secara teratur ketika semakin menjauhi pusat kota 
(Ratcliff, 1949). Sedangkan menurut Brian J.Berry (1967) menyatakan bahwa selain faktor lokasi, harga tanah juga ditentukan oleh adanya perpotongan jaringan jalan terutama radial road dan ring road. Teori ini sesuai untuk menggambarkan kondisi kawasan Perkotaan Banjarmasin yang memiliki ring road atau jalan lingkar. Karena pada prinsipnya, peningkatan aksesibilitas suatu kawasan (dalam hal ini misalnya pembangunan atau pelebaran jalan) akan diikuti dnegan meningkatnya harga tanah kawasan tersebut. [19]

pada penelitian ini mencoba menerapkan algoritma jaringan syaraf tiruan untuk mendapatkan perkiraan harga tanah yang ideal, dengan lokasi penelitian di kota Banjarmasin. Adanya hasil dari penelitian ini diharapkan dapat digunakan membantu pemerintah terkait pembebasan tanah dalam besarnya ganti rugi hak atas tanah yang hanya cenderung berdasarkan Nilai Jual Obyek Pajak (NJOP).

\section{RUMUSAN MASALAH}

Berdasarkan identifikasi masalah diatas maka perlu dilakukan pengujian terhadap Algoritma Jaringan Syaraf Tiruan untuk mengetahui keakuratan dalam menentukan harga tanah dikota Banjarmasin. Adapan rumusan masalahnya sebagai berikut "Sejauh mana akurasi pada RMSE untuk Algoritma Jaringan Syaraf Tiruan dalam mengestimasi harga tanah yang mendekati harga yang ideal agar memperoleh "penilaian" atas kepemilikan tanah secara obyektif dan transparan, baik untuk transaksitransaksi pertanahan (jual beli, agunan, asuransi, sewa-kontrak, dan sebagainya), pembayaran pajak, maupun dalam perolehan kompensasi atau ganti kerugian akibat pengadaan tanah untuk kepentingan umum".

\section{TUJUAN PENELITIAN}

Penelitian ini bertujuan untuk melakukan penerapan algoritma jaringan syaraf tiruan (JST), dalam mengestimasi atau memperkirakan harga tanah yang mendekati harga ideal.

\section{MANFAAT PENELITIAN}

Penelitian ini dilakukan dengan harapan agar bisa memberikan manfaat tertentu baik bagi penulis, serta bagi pihak lain yang membutuhkan. Adapun manfaat dari penelitian ini adalah sebagai berikut: 1. Manfaat praktis penentuan harga tanah dalam bentuk algoritma jaringan syaraf tiruan (JST) akan menghasilkan nilai tanah yang lebih wajar dan mendekati harga sebenarnya sehingga dapat membantu meningkatkan kualitas pelayanan publik dalam bidang pertanahan dan meningkatkan kesejahteraan masyarakat. Dengan mengetahui pengaruh atribut jaringan jalan dan guna lahan, penelititan ini dapat dimanfaatkan untuk memperkirakan harga tanah di kawasan Banjarmasin dengan lebih baik berdasakan model harga tanah yang dirumuskan dalam penelitian ini.

2. Manfaat teoritis hasil penelitian ini diharapkan dapat memberikan sumbangsih ilmu pengetahuan bagi pengembangan teori dan metode yang berkaitan dengan Kebijakan Penilaian Tanah atau berkaitan dengan harga dasar tanah di Indonesia khusus nya untuk menentukan pajak atas lahan dan bangunan dengan lebih tepat sesuai nilai dan fungsi lahan yang sebenarnya.

3. Manfaat kebijakan dari hasil penelitian ini diharapkan dapat menjadi sumbangan pengetahuan bagi lembaga terkait selain metode-metode yang sudah ada dan dengan 
mengetahui harga lahan secara akurat, maka perkembangan kawasan perkotaan akan dapat diprediksi dengan mudah serta dapat dimanfaatkan oleh bidang ilmu perencanaan sebagai pedoman khususnya perencanaan tata guna lahan dan transportasi.

4. Sebagai acuan bagi peneliti selanjutnya khususnya yang terkait dengan penelitian tentang penentuan harga tanah di Indonesia.

\section{KERANGKA PEMIKIRAN}

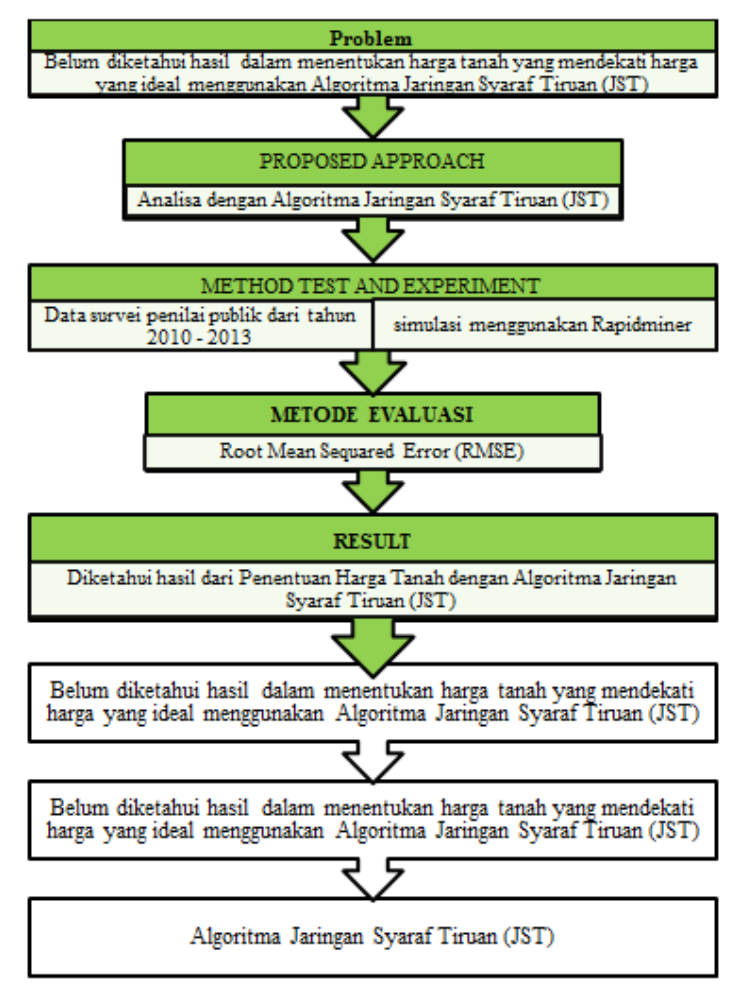

\section{PENGUMPULAN DATA}

Pengumpulan data yang digunakan oleh peneliti dalam mengumpulkan harga tanah di kota Banjarmasin adalah Data Primer. Data Primer yaitu data yang diperoleh secara langsung dari sumbernya seperti penjual/masyarakat, developer dan appraisal independen pertanahan di kota Banjarmasin.
Data yang digunakan dalam penelitian ini adalah harga penawaran tanah dengan total 402 data dan 6.817 record yang berada di kota Banjarmasin dari tahun 2010 sampai dengan tahun 2013.

Dari tabel daftar Harga Penawaran Tanah, dipilih atribut yang digunakan sebagai acuan dalam perhitungan dan pengolahan data, atribut yang digunakan adalah Penawaran Total yang sudah mengalami penyesuaian dari beberapa faktor yaitu tahun tanah, luas tanah, luas bangunan, harga tanah dari penawaran per $\mathbf{M}^{2}$, posisi letak tanah, dan status kepemilikan.

Data tersebut kemudian dilakukan preprosesing dengan tujuan untuk menambah keakuratan metode yang akan digunakan. Pre-prosesing adalah langkah awal dalam pengolahan data untuk membantu metode yang digunakan agar dapat berjalan dengan baik dan menghasilkan faktor kesalahan (RMSE) yang rendah.

\section{METODE YANG DIUSULKAN}

Metode yang diusulkan menggunakan Algoritma Jaringan Syaraf Tiruan (JST) yang diharapkan memiliki faktor kesalahan (RMSE) yang rendah dalam melakukan prediksi untuk penetapan harga tanah yang ideal di kota Banjarmasin. Penggunaan backpropagation disini bertujuan untuk mendapatkan keseimbangan antara pengenalan pola pelatihan secara benar dan respon yang baik untuk pola lain yang sejenis (disebut data pengujian). Data yang digunakan adalah daftar harga penawaran tanah tahun 2010 sampai dengan 2013 yang akan dibagi menjadi dua yaitu sebagai data training dan data testing. Backpropagation yang dioptimalkan akan memiliki minimum error untuk setiap traning data yang diberikan. 


\section{HASIL PENELITIAN}

Hasil penelitian perkiraan harga tanah menggunakan penerapan Algoritma Jaringan Syaraf Tiruan (JST) dengan hasil Root Mean Square Error (RMSE) terendah berada di eksperimen ketiga yang menggunakan data training $70 \%$ dan data testing $30 \%$ dengan K-Fold validasi 2 dan 3 dengan hasil 788352204.112 dari atribut label penawaran total yang menjadi acuan harga tanah ideal dikota Banjarmasin.

\section{IMPLIKASI PENELITIAN}

Berdasarkan hasil penelitian dan pengujian di daerah studi kota Banjarmasin dengan data penawaran harga tanah tahun 2010 hingga tahun 2013 yang diimplementasikan kedalam Algoritma Jaringan Syaraf Tiruan (JST) untuk menentukan harga tanah yang ideal ternyata belum mampu memberikan solusi bagi appraisal, developer, maupun instansi terkait lainnya untuk membantu memberikan gambaran harga mendekati ideal khususnya masalah harga tanah di kota Banjarmasin

\section{KESIMPULAN}

Dari hasil penelitian tersebut dapat disimpulkan bahwa :

1. Algoritma Jaringan Syaraf Tiruan (JST) dapat memberikan hasil atau pengukuran dari prediksi penentuan harga tanah di kota Banjarmasin namun belum begitu sempurna karena menghasilkan nilai RMSE yang cukup besar.

2. Algoritma Jaringan Syaraf Tiruan (JST) dengan hasil Root Mean Square Error (RMSE) terendah berada di eksperimen ketiga yang menggunakan data training $70 \%$ dan data testing $30 \%$ dengan K-Fold validasi 2 dan 3 dengan hasil 788352204.112.

3. Pre-prosesing yang dilakukan pada pengolahan data awal terhadap data set dapat menurunkan nilai tingkat error (RMSE) disetiap eksperimen yang dilakukan.

\section{SARAN}

Analisis mengenai prediksi penentuan harga tanah yang ideal dikota Banjarmasin menggunakan Algoritma Jaringan Syaraf Tiruan (JST) ini hanya memprediksi berdasarkan nilai error sebagai faktor uji.

Dari hal tersebut untuk penelitian dan pengujian yang akan datang agar hasil yang didapat jauh lebih baik maka perlu diperhatikan :

a. Data yang digunakan sebagai data set untuk masukan sistem, di ambil dari beberapa titik atau beberapa kota pengamatan terutama di kota yang mempunyai struktur atau susunan tanah yang hampir sama dengan kota yang diteliti.

b. Perlu pengambilan data uji dalam jumlah yang lebih banyak.

c. Perlu melakukan pengujian dengan algoritma Logistic Regression atau Support Vector Machines untuk membandingkan hasil terbaik disetiap metode.

\section{DAFTAR PUSTAKA}

[1] Cakrawala berita (online) (http://cakrawalaberita.com/catatancakrawala/infrastruktur-indonesiatertinggal-jauh).

[2] Pengkajian Berkas DPR http://berkas.dpr.go.id/pengkajian/fil es/jurnal_kepakaran/Negara\%20Huk um-3-1-Juni- 
2012.pdfDesember2014].

rs/junluocompetition04.pdf.

[3] Tempo(online)

http://www.tempo.co/read/news/2011

/04/13/090327120/Pembangunan-

Jalur-Kereta-Lingkar-Luar-Jakarta-

Tunggu-Masterplan).

[4] liputan6 (online)

http://bisnis.liputan6.com/read/47162

3/8-lahan-tol-kebon-jeruk-ulujami-

sulit-dibebaskan)

[5] Direktorat Survey Potensi Tanah BPN, Standar Operasional Prosedur, 2011, Jakarta.

[6] Rizal, M. Syamsul. Perbandingan Penilaian Tanah Antara Metode Kriging dengan Peta Zone Nilai Tanah, Tesis S2, Pasca Sarjana UDINUS, Semarang, 2012.

[7] Imawan, Diddy Wahyudi. Pengembangan Metoda Penilaian

[9] Dewi Kania, et al. "Pemodelan Harga Tanah PerkotaanMenggunakan Metode Geostatistika (Daerah Studi: Kota Bandung) “ Jurnal rekayasa, LPPM Itenas, No.2 Vol. XIV,Jakarta, 2010.

[10] Mappi, Standar Penilaian Indonesia, 2007

[11] Darmawan, Dalu Agung, Konsepsi Dan Studi Empiris Tentang Harga Tanah, Pusat Penelitian dan Pengembangan BPN, Jakarta, 2005

[12] Ekel, Patrick A dan R. Agus Mahendra, Studi Assesment Ratio Nilai Jual Obyek Pajak (NJOP) Tanah Terhadap Harga Tanah Di Kota Surakarta, Bhumi Nomor 9 tahun 4: 5673, 2004

Tanah dengan Menggunakan Analisis Spasial dan Jaringan Syaraf Tiruan, Tesis S2, Pasca Sarjana, ITB, Bandung, 2007,

[8] Luo, J. (2004). Modelling Urban Land Value in GIS Environment. Dalam http://www.uwm.edu/Dept/GIS/flye 